\title{
Investigation on the Performance of a Solar Hybrid Refrigeration System Using Environmentally Friendly Fluids
}

\author{
Latra Boumaraf*, Rachedi Khadraoui \\ LR3MI, Department of Mechanical Engineering, Badji Mokhtar University BP 12, Annaba 23000, Algeria
}

Corresponding Author Email: boumaraf.latra@univ-annaba.dz

https://doi.org/10.18280/ijht.380423

Received: 20 October 2019

Accepted: 5 September 2020

\section{Keywords:}

hybrid refrigeration cycle, ejector, solar energy, environmentally friendly fluids, modeling

\begin{abstract}
In order to evaluate the performance of a hybrid compression / ejection refrigeration system using solar energy at low or medium temperature, a simulation model of its behavior based on those of its various components has been developed. It includes in particular for the ejector, a 1-D model of the "constant section mixing" type developed in optimal transition regime. The refrigerants tested are steam for the ejector loop and the R1234yf (replacing the $\mathrm{R} 134 \mathrm{a}$ ) for the mechanical compression loop. The behavior of the $\mathrm{H}_{2} \mathrm{O}$ vapor flowing in the ejector is considered that of the perfect gas. The properties of refrigerants are calculated using REFPROP ${ }^{\circledR}$ software, everywhere else. For a cooling capacity of $10 \mathrm{~kW}$ and air conditioning operating conditions, the model allows to determine the main parameters of the ejector and its entrainment ratio, the thermal and mechanical $C O P$ of the whole refrigeration system as well as the necessary surface of the solar collector. Furthermore, the influence of the temperature of the boiler, the condenser, the intercooler as well as that of the evaporator on the mechanical $C O P$ of the hybrid system and the solar collection surface in particular, were examined. The results highlight that the solar refrigeration system with hybrid cycle compression/ejection using the refrigerants $\mathrm{H}_{2} \mathrm{O} / \mathrm{R} 1234 y f$ allows an increase of the mechanical COP higher than 50\% compared to that of the conventional refrigeration system and thus constitutes an acceptable ecologically system that can compete with the latter.
\end{abstract}

\section{INTRODUCTION}

In the context of sustainable development, the use of an ejector refrigeration system [1] for the production of cold (refrigeration and air conditioning) combines two advantages, one related to the energy saving due to the use of a free energy source (solar energy or heat discharges from industrial processes) and the other related to the protection of the environment through the reduction of $\mathrm{CO}_{2}$ emissions in the atmosphere. In addition, this type of system is more suitable for the use of refrigerants more environmentally friendly (natural or synthetic with low environmental impact). However, its coefficient of performance, $C O P$ is closely related to the performance of the ejector determined by its entrainment rate, $U$ which is often mediocre. Several studies [2-8] have focused on improving the latter, which is a function of the operating conditions of the system, the geometric parameters of the ejector and the nature of the working fluid. For this purpose, the use of a hybrid refrigeration system compression/ejection overcomes this disadvantage [9]. Indeed, the latter allows combining the advantages and eliminating the disadvantages of both ejector and vapor compression subsystems. In order to evaluate and optimize the performance of this system, a simulation model of its thermodynamic cycle has been developed. It includes, for the ejector, a 1-D model based on the equations of mass conservation, balance momentum and energy conservation, of "constant section mixing" type in transition mode, developed previously [10-12]. $\mathrm{H}_{2} \mathrm{O}$ is used as a refrigerant in the ejector sub-cycle and the
$\mathrm{R} 1234 \mathrm{yf}(O D P=0$ and $G W P=4)$ replacing the $\mathrm{R} 134 \mathrm{a}(O D P$ $=0$ and $G W P=1430)$ is used in the mechanical vapor compression sub-cycle. The reference operating temperatures of the generator (boiler), the condenser, the intercooler and the evaporator are respectively set at $T_{\mathrm{B}}=80^{\circ} \mathrm{C}, T_{\mathrm{C}}=40^{\circ} \mathrm{C}, T_{\text {int }}=$ $30^{\circ} \mathrm{C}$ and $T_{\mathrm{E}}=5^{\circ} \mathrm{C}$. The cooling capacity selected is $10 \mathrm{~kW}$. The entrainment ratio $U$ and the main geometrical parameters of the ejector as well as the thermal performance coefficient, $C O P_{\text {th }}$ and the mechanical performance coefficient, $C O P_{\text {mec }}$ of the ejection/compression hybrid cycle refrigeration system are then calculated. Furthermore, the influence of the temperature of the boiler, the condenser, the intercooler as well as that of the evaporator on the mechanical $C O P$ of the hybrid system and the solar collector surface in particular, were examined.

\section{SOLAR REFRIGERATION SYSTEM WITH HYBRID EJECTION/COMPRESSION CYCLE}

The cycle of a hybrid ejection/compression refrigeration system (Figure 1) consists of a sub-cycle of an ejector refrigeration system (Figure 2(a)) connected to that of a vapor compression system (Figure 2(b)). Steam is used as a refrigerant in the first sub-cycle while R1234yf is used in the second one. The connection between the two sub-cycles is ensured by the intercooler which serves as an evaporator for the ejector sub-cycle and a condenser for the vapor compression sub-cycle. Its operating temperature $T_{\text {int }}$ is between the temperature of the evaporator $T_{\mathrm{E}}$ and that of the condenser $T_{\mathrm{C}}$ of the hybrid cycle. 


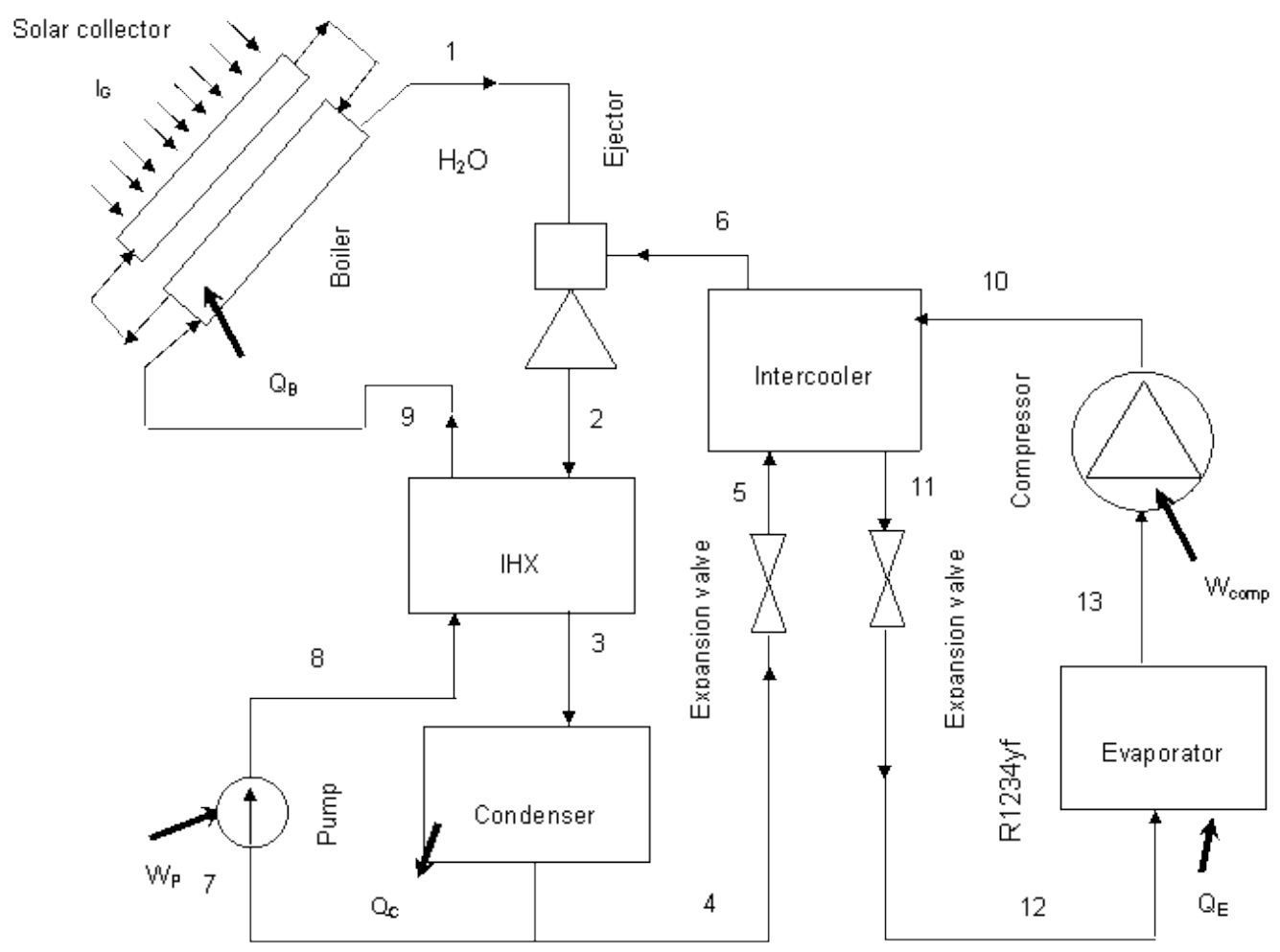

Figure 1. Diagram of the hybrid ejection/compression refrigeration system

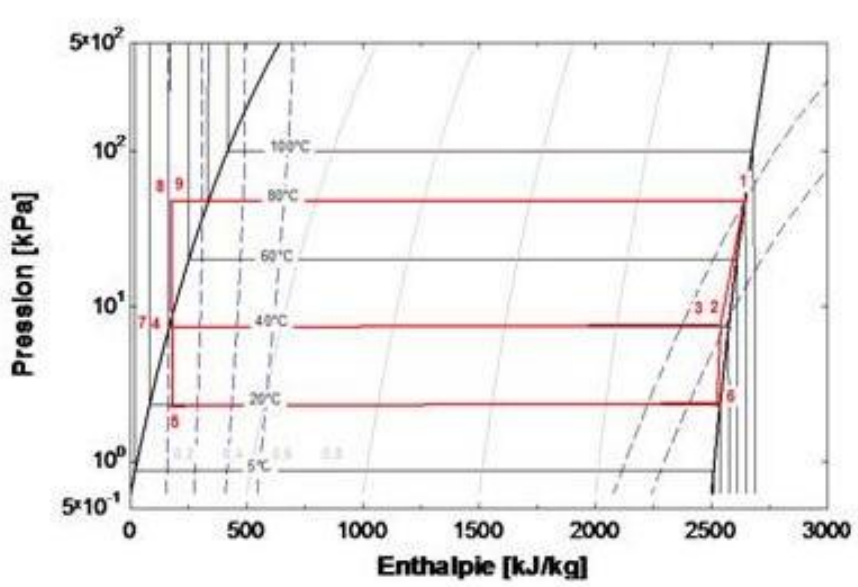

(a)

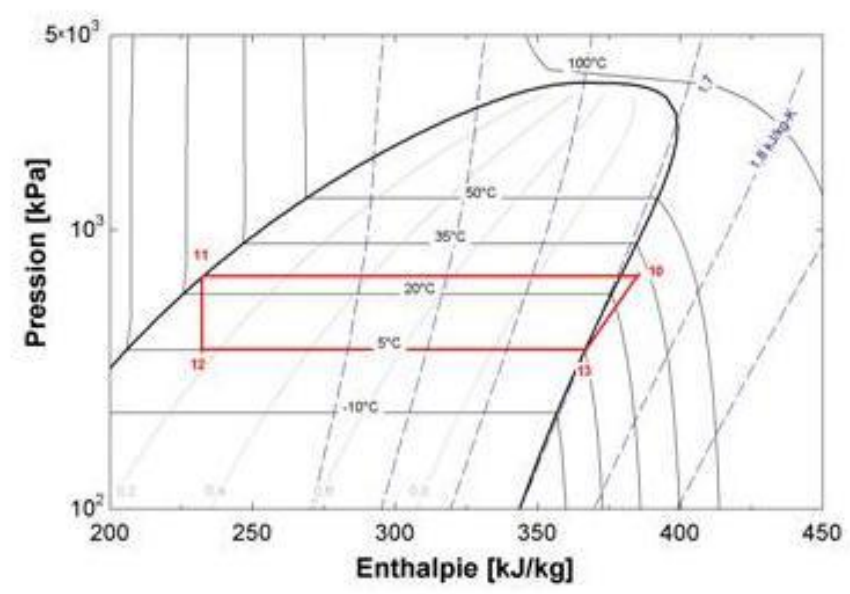

(b)

Figure 2. Diagrams of the ejector (a) and vapor compression (b) sub-cycles of the hybrid ejection/compression refrigeration system
Figure 3 depicts the configuration of the ejector used. An ejector is a static system composed by a primary nozzle whose throat and outlet diameters are respectively $d_{\mathrm{P}}^{*}$ and $d_{\mathrm{P}}$. This socalled motive nozzle is disposed in a secondary nozzle, which includes a suction chamber, a mixing chamber (tube cylindrical with diameter $d_{\mathrm{m}}$ ) and a diffuser with an outlet diameter of $d_{\mathrm{D}}$.

The operating cycle of the hybrid ejection/compression refrigeration system is as follows: the supply of thermal energy, $Q_{\text {B }}$ to the boiler from a solar collector, is used to produce $\mathrm{H}_{2} \mathrm{O}$ vapor at high temperature and high pressure (state 1) called primary or motive fluid (P) which expands in the ejector primary nozzle (Figure 3). At the outlet, the high-speed primary fluid drives the vapor $\mathrm{H}_{2} \mathrm{O}$ called secondary fluid (S) from the intercooler in state 6 . Then, the primary and secondary flows mix in the mixing chamber. A first pressure increase due to the formation of a Normal Shock Wave (NSW) takes place in the mixing chamber followed by a second due to compression in the diffuser. At the outlet of the latter, the mixture of superheated steam (state 2) passes into a heat exchanger where its temperature is reduced to that of state 3 , before entering the condenser where it passes in liquid form. The condensation heat, $Q_{\mathrm{C}}$ is rejected to the surrounding environment. A part of the condensate, state 4, passes through an expansion device to the state 5 and then enters the intercooler where it is evaporated by the condensation heat of the vapor compression refrigeration sub-cycle operating with the fluid R1234yf. The remainder of condensate $\mathrm{H}_{2} \mathrm{O}$, state 7, is pumped by a circulation pump, state 8 to the boiler, state 9 , via the heat exchanger, IHX where it recovers the sensible heat of the $\mathrm{H}_{2} \mathrm{O}$ vapor from the ejector. In the vapor compression sub-cycle, the R1234yf vapor from the compressor, state 10, is condensed at the liquid form, state 11 , in the intercooler. The heat of this condensation is used to vaporize the refrigerant from the ejector sub-cycle. The condensate, state 11, first undergoes a pressure reduction to that of the state 12 at the passage of an expansion device before entering the evaporator to produce the expected cooling effect $Q_{\mathrm{E}}$. At the exit of the 
latter, R1234yf in the state 13 is compressed by the compressor to the state 10 before entering the intercooler, which completes the hybrid ejection/compression cycle.

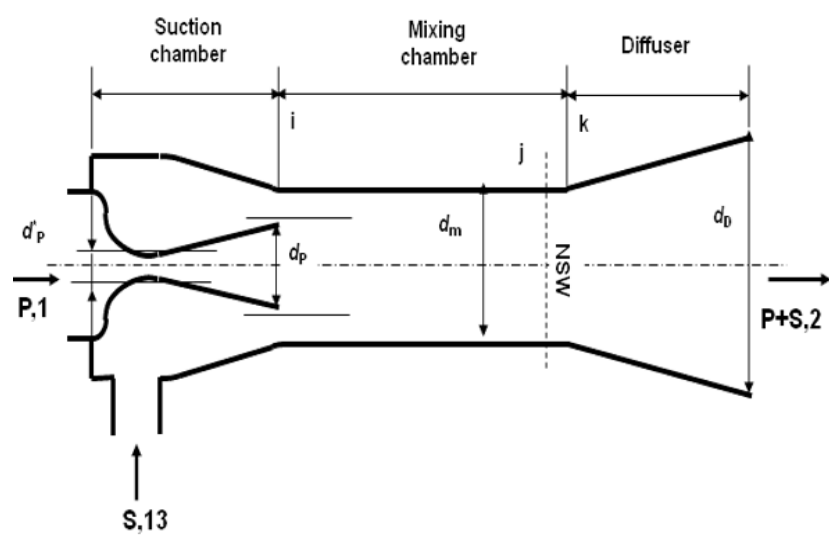

Figure 3. Configuration of the ejector

\section{MODELING}

\subsection{Assumptions}

The purpose of the modeling is to determine the thermodynamic characteristics of the fluids (steam and R1234yf) at the various points of the ejector and vapor compression sub-cycles. For this, the following assumptions are made:

- The steams at the outlet of the generator, the intercooler and the evaporator as well as the liquids at the outlet of the condenser and the intercooler are saturated.

- The throttling processes in the expansion valves are considered to be isenthalpic.

- The compressor has a given isentropic efficiency $\left(\eta_{\text {comp }}=\right.$ $0.75)$.

- The heat exchanger has a thermal efficiency of $80 \%$ and the pump has a mechanical efficiency of $50 \%$.

Moreover, to determine the state of the refrigerant at the inlet of the condenser, it is necessary to model the ejector operation. The assumptions adopted for the study of the ejector are essentially:

- The steam flow in the ejector is considered as that of the perfect gas, everywhere else, the properties of the refrigerants are calculated using the software REFPROP ${ }^{\circledR}$ [13].

- The velocities of the primary fluid at the inlet of the ejector and the mixture at the outlet of the diffuser are assumed to be equal to an arbitrary value of $1 \mathrm{~m} / \mathrm{s}$ (this allows a complete sizing of the ejector); that of the secondary fluid at the entrance of the ejector is neglected.

- The motive fluid reaches sonic velocity at the primary nozzle throat section.

- The pressure on the plane (i) is assumed to be uniform and equal to that corresponding to the secondary flow choking at the beginning of the mixing process (transition mode).

- The normal shock wave takes place in the cylindrical tube of the secondary nozzle.

- The primary nozzle, the suction chamber of the secondary nozzle and the diffuser have given isentropic efficiencies (respectively $\eta_{P}=0.95, \eta_{S}=0.95$ and $\eta_{D}=0.8$ ) and the friction losses in the mixing chamber are neglected.

\subsection{Ejector model}

The mathematical equations of the ejector model are obtained by applying the principles of conservation of mass, energy as well as the balance of momentum at judiciously chosen control volumes.

The speed of the primary fluid $(\mathrm{P})$ at the outlet of the convergent-divergent (plane $\mathrm{i}$ ) is given by:

$$
V_{\mathrm{Pi}}=\sqrt{2 \eta_{\mathrm{P}}\left(h_{\mathrm{P} 1}-h_{\mathrm{Pi}}\right)_{\mathrm{is}}+V_{\mathrm{P} 1}^{2}}
$$

The area of the motive flow at the primary nozzle throat, $A_{\mathrm{P}}{ }^{*}$ and that before mixing (plane $\mathrm{i}$ of the ejector), $A_{\mathrm{Pi}}$ are computed by:

$$
\begin{gathered}
A_{\mathrm{P}}^{*}=\frac{\dot{m}_{\mathrm{P}}}{\rho_{\mathrm{P}}^{*} \sqrt{2 \eta_{\mathrm{P}}\left(h_{\mathrm{P} 1}-h_{\mathrm{P}}^{*}\right)_{\mathrm{is}}}} \\
A_{\mathrm{Pi}}=\frac{\dot{m}_{\mathrm{P}}}{\rho_{\mathrm{Pi}} \sqrt{2 \eta_{\mathrm{P}}\left(h_{\mathrm{P} 1}-h_{\mathrm{Pi}}\right)_{\mathrm{is}}}}
\end{gathered}
$$

The speed of the secondary fluid (S) at the mixing chamber inlet (plane i) is given by:

$$
V_{\mathrm{Si}}=\sqrt{2 \eta_{\mathrm{S}}\left(h_{\mathrm{S} 6}-h_{\mathrm{Si}}\right)}
$$

The area of the secondary flow before mixing (plane $i$ of the ejector) is given by:

$$
A_{\mathrm{Si}}=\frac{\dot{m}_{\mathrm{S}}}{\rho_{\mathrm{Si}} \sqrt{2 \eta_{\mathrm{S}}\left(h_{\mathrm{S} 6}-h_{\mathrm{Si}}\right)_{\text {is }}}}
$$

The speed of the mixture $V_{\mathrm{j}}$ is determined from the balance of the momentum between the planes $\mathrm{i}$ and $\mathrm{j}$ :

$$
V_{\mathrm{j}}=\frac{V_{\mathrm{Pi}}+U V_{\mathrm{Si}}}{(1+U)}+\frac{P_{\mathrm{Pi}} A_{\mathrm{Pi}}+P_{\mathrm{Si}} A_{\mathrm{Si}}-P_{\mathrm{j}} A_{\mathrm{i}}}{(1+U) \dot{m}_{\mathrm{P}}}
$$

With: $A_{\mathrm{i}}=A_{\mathrm{Pi}}+A_{\mathrm{Si}}$.

The enthalpy $h_{\mathrm{j}}$ (or temperature $T_{\mathrm{j}}$ ) of the mixture is according to the principle of energy conservation:

$$
h_{\mathrm{j}}=\frac{h_{\mathrm{Pi}}+1 / 2 V_{\mathrm{Pi}}{ }^{2}+U\left(h_{\mathrm{Si}}+1 / 2 V_{\mathrm{Si}}{ }^{2}\right)-1 / 2 V_{\mathrm{j}}{ }^{2}}{(1+U)}
$$

The corresponding Mach number $M_{\mathrm{j}}$ is then:

$$
M_{\mathrm{j}}=\frac{V_{\mathrm{j}}}{\sqrt{\gamma R T_{\mathrm{j}}}}
$$

The Mach number of the fluid after passage of the shock wave $M_{\mathrm{k}}$ and the compression ratio $P_{\mathrm{k}} / P_{\mathrm{j}}$ are:

$$
M_{\mathrm{k}}=\sqrt{\frac{1+((\gamma-1) / 2) M_{\mathrm{j}}^{2}}{\gamma M_{\mathrm{j}}^{2}-((\gamma-1) / 2)}}
$$




$$
\frac{P_{\mathrm{k}}}{P_{\mathrm{j}}}=1+\frac{2 \gamma}{\gamma+1}\left(M_{\mathrm{j}}^{2}-1\right)
$$

The enthalpy $h_{2}$ and the pressure $P_{2}$ of the mixture at the outlet of the diffuser are determined from the following equations:

$$
\begin{gathered}
h_{2}=\frac{h_{\mathrm{P} 1}+1 / 2 V_{\mathrm{P} 1}^{2}+U h_{\mathrm{S} 6}-1 / 2 V_{2}{ }^{2}}{(1+U)} \\
\eta_{\mathrm{D}}=\frac{\left(h_{2, \mathrm{is}}-h_{\mathrm{k}}\right)}{\left(h_{2}-h_{\mathrm{k}}\right)} \\
P_{2}=f\left(s_{2, \text { is }}, h_{2, \text { is }}\right)
\end{gathered}
$$

\subsection{Vapor compression sub-cycle model}

The cooling capacity $\dot{Q}_{\mathrm{E}}$ is fixed; the mass flow rate of R1234yf circulating in the evaporator $\dot{m}_{\mathrm{E}}$ is given by:

$$
\dot{m}_{\mathrm{E}}=\frac{\dot{Q}_{\mathrm{E}}}{\left(h_{13}-h_{12}\right)}
$$

The enthalpy of the refrigerant at the compressor outlet $h_{10}$ is determined from the following equations:

$$
\eta_{\text {comp }}=\frac{\left(h_{10, \text { is }}-h_{13}\right)}{\left(h_{10}-h_{13}\right)}
$$

With: $h_{10, \text { is }}=f\left(P_{10}, s_{13}\right)$.

Consequently, the compressor consumption power is:

$$
\dot{W}_{\text {comp }}=\dot{m}_{\mathrm{E}}\left(h_{10}-h_{13}\right)
$$

The secondary mass flow rate of the ejector $\dot{m}_{\mathrm{S}}$ is calculated from the energy balance of the intercooler:

$$
\dot{m}_{\mathrm{S}}=\frac{\dot{m}_{\mathrm{E}}\left(h_{10}-h_{11}\right)}{\left(h_{6}-h_{5}\right)}
$$

\subsection{Ejector sub-cycle model}

The enthalpy of liquid water at the pump outlet (point 8 ) is determined by:

$$
h_{8}=h_{7}+\frac{\left(P_{8}-P_{7}\right)}{\rho_{7}}
$$

Then, the pump consumption power is:

$$
\dot{W}_{\mathrm{P}}=\frac{\dot{m}_{\mathrm{P}}\left(h_{8}-h_{7}\right)}{\eta_{\mathrm{P}}}
$$

The steam temperature $T_{3}$ at the outlet of the heat exchanger is calculated from the efficiency $\varepsilon$ of the latter:

$$
\varepsilon=\frac{T_{2}-T_{3}}{T_{2}-T_{8}}
$$

The enthalpy of liquid water at the boiler inlet (point 9) is calculated from the energy balance of the IHX:

$$
h_{9}=h_{8}+(1+U)\left(h_{3}-h_{2}\right)
$$

With: $h_{3}=f\left(P_{3}=P_{\mathrm{C}}, T_{3}\right)$.

\subsection{Performance of the hybrid ejection/compression refrigeration cycle}

The performance of the hybrid refrigeration system is evaluated using the thermal performance coefficient $\left(C O P_{\text {th }}\right)$ and the mechanical one $\left(C O P_{\mathrm{mec}}\right)$ defined respectively by Eqns. (22) and (24):

$$
C O P_{\mathrm{th}}=\frac{\dot{Q}_{\mathrm{E}}}{\dot{Q}_{\mathrm{B}}+\dot{W}_{\mathrm{P}}+\dot{W}_{\mathrm{comp}}}
$$

where, $\dot{Q}_{\mathrm{B}}$ is the thermal power of the boiler given by:

$$
\dot{Q}_{\mathrm{B}}=\dot{m}_{\mathrm{P}}\left(h_{1}-h_{9}\right)
$$

$$
C O P_{\mathrm{mec}}=\frac{\dot{Q}_{\mathrm{E}}}{\dot{W}_{\mathrm{P}}+\dot{W}_{\mathrm{comp}}}
$$

Furthermore, the area of the solar collector $A_{\mathrm{SC}}$ can be determined by:

$$
A_{\mathrm{SC}}=\frac{\dot{Q}_{\mathrm{B}}}{I_{\mathrm{G}} \eta_{\mathrm{SC}}}
$$

where, $I_{\mathrm{G}}$ is the global incident radiation assumed to be constant and equal to $900 \mathrm{~W} / \mathrm{m}^{2}$ and $\eta_{\mathrm{SC}}$ the efficiency of the solar collector estimated at $50 \%$ [14].

\section{CALCULATION PROCEDURE}

Steam superheating at the outlet of the boiler (point 1), the intercooler (point 6) and the evaporator (point 13) as well as the liquid subcooling at the outlet of the condenser (points 4 and 7) and the intercooler (point 11) are assumed to be zero; the thermodynamic properties at these points are determined using the phase change temperatures of the boiler $T_{\mathrm{B}}$, the condenser $T_{\mathrm{C}}$, the intercooler $T_{\text {int }}$ and the evaporator $T_{\mathrm{E}}$. In addition, the refrigeration capacity $\dot{Q}_{\mathrm{E}}$ being fixed, the application of the vapor compression, sub-cycle model allows to calculate the power consumption of the compressor (Eq. (16)), the secondary mass flow rate $\dot{m}_{\mathrm{S}}$ (Eq. (17)) which is an input data for the ejector model. The use of the latter leads to the determination of the main geometric parameters of the ejector, its entrainment ratio $U$ (or primary mass flow rate $\dot{m}_{\mathrm{P}}$ ) and the thermodynamic properties of the steam at the outlet of the diffuser (state 2). The ejector sub-cycle model uses the output parameters of the previous model to calculate the consumption power of the pump (Eq. (19)) as well as the 
thermal power of the boiler (Eq. (23)). Finally, the Eqns. (22), (24) and (25) allow determining respectively the $C O P_{\text {th }}$, the $C O P_{\text {mec }}$ and the surface of the solar collector $A_{\mathrm{SC}}$.

\section{RESULTS AND DISCUSSION}

On Figure 4, the variations of the entrainment ratio of the ejector $U$, the $C O P_{\text {th }}$ and the $C O P_{\mathrm{mec}}$ of the hybrid refrigeration system are represented as a function of the condenser temperature $T_{\mathrm{C}}$. It can be seen that the values of $U$ and $C O P_{\text {th }}$ are higher than those usually encountered in a basic ejector refrigeration system operating in the same conditions. This can be explained by the increase in the pressure of the secondary fluid at the inlet of the ejector into the hybrid refrigeration system. Furthermore, on the same figure, the $C O P_{\text {mec }}$ of the hybrid system is compared to the $C O P_{\text {mec }}$ of the conventional vapor compression refrigeration system operating at the same temperatures of the condenser and the evaporator. These results clearly show that in a "useful" temperature range of the condenser, the $C O P_{\mathrm{mec}}$ of the hybrid system is higher than the $C O P_{\text {mec }}$ of the conventional vapor compression system. Indeed, for a condenser temperature varying between 35 and $50^{\circ} \mathrm{C}$, the increase in $C O P_{\text {mec }}$ varies from 61 to $42 \%$.

This electrical energy saving achieved in the hybrid system is in fact provided in thermal form by the solar collector.

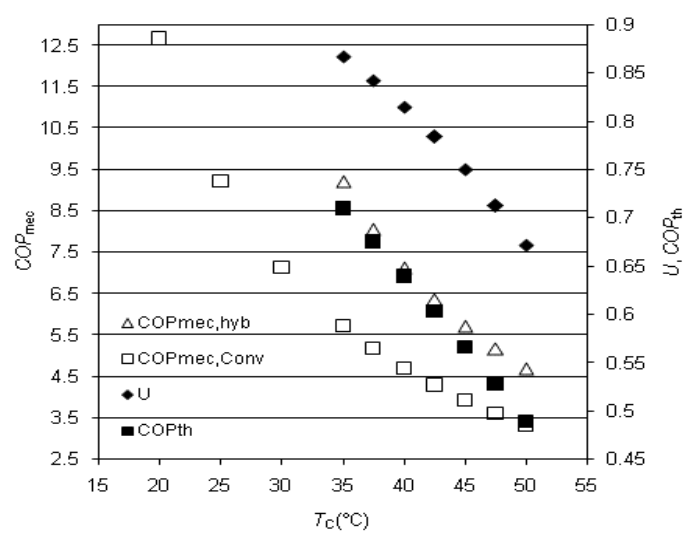

Figure 4. Variations of $U, C O P_{\mathrm{th}}, C O P_{\mathrm{mec}}$ of the hybrid refrigeration system and $C O P_{\mathrm{mec}}$ of the conventional system as a function of $T_{\mathrm{C}}$ for $T_{\mathrm{B}}=80^{\circ} \mathrm{C}, T_{\text {int }}=T_{\mathrm{C}}-10$ and $T_{\mathrm{E}}=5^{\circ} \mathrm{C}$

Figure 5 highlights the fact that the more the mechanical performance of the hybrid system degrades $\left(C O P_{\text {mec }}\right.$ decreases) with the increase of the condenser temperature the more the surface of the solar collector increases to produce the same imposed cooling capacity $(10 \mathrm{~kW})$.

Logically, Figure 6 shows that the level of the boiler temperature, $T_{\mathrm{B}}$ has no influence on the $C O P_{\text {mec }}$ of the hybrid system and that the surface of the solar collector, $A_{\mathrm{SC}}$ increases when $T_{\mathrm{B}}$ decreases.

At $T_{\mathrm{B}}, T_{\mathrm{C}}$ and $T_{\mathrm{E}}$ fixed Figure 7 shows that $U$ and the $C O P_{\text {th }}$ increase with the temperature of the intercooler $T_{\text {int }}$ while the $C O P_{\text {mec }}$ decreases with the latter. This can be explained by the fact that the intercooler acts as an evaporator for the ejector loop and as a condenser for the vapor compression loop. This figure also shows that the curves representing the variations of $C O P_{\text {th }}$ and $C O P_{\text {mec }}$ as a function of $T_{\text {int }}$ intersect at a point whose value of $T_{\mathrm{int}}$ is equal to approximately $T_{\mathrm{C}}-10$ leading to the optimal performance of the hybrid ejection /compression refrigeration system.

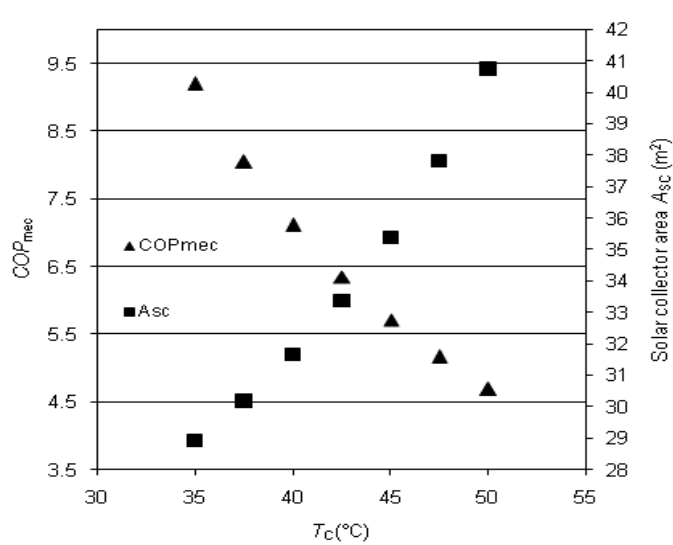

Figure 5. Variations of the $C O P_{\text {mec }}$ of the hybrid refrigeration system and the solar collector surface $A_{\mathrm{SC}}$ as a function of $T_{\mathrm{C}}$ for $T_{\mathrm{B}}=80^{\circ} \mathrm{C}, T_{\mathrm{int}}=T_{\mathrm{C}}-10$ and $T_{\mathrm{E}}=5^{\circ} \mathrm{C}$

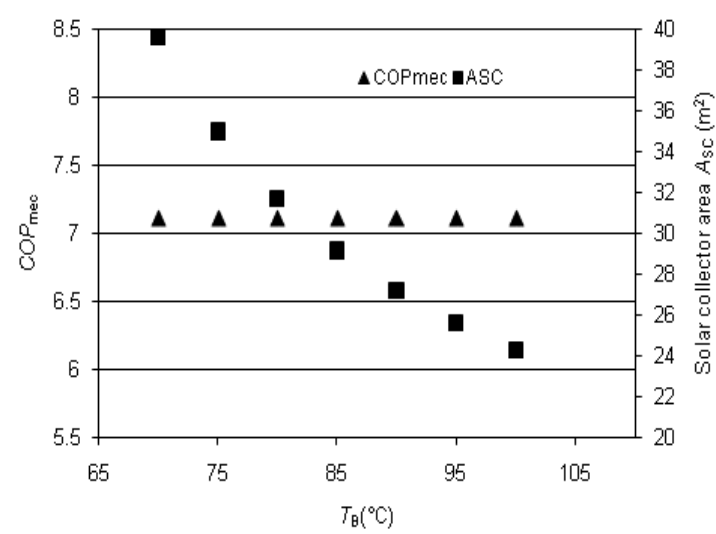

Figure 6. Variations of $C O P_{\mathrm{mec}}$ of the hybrid refrigeration system and the solar collector surface $A_{\mathrm{SC}}$ as a function of $T_{\mathrm{B}}$ for $T_{\mathrm{C}}=40^{\circ} \mathrm{C}, T_{\mathrm{int}}=30^{\circ} \mathrm{C}$ and $T_{\mathrm{E}}=5^{\circ} \mathrm{C}$

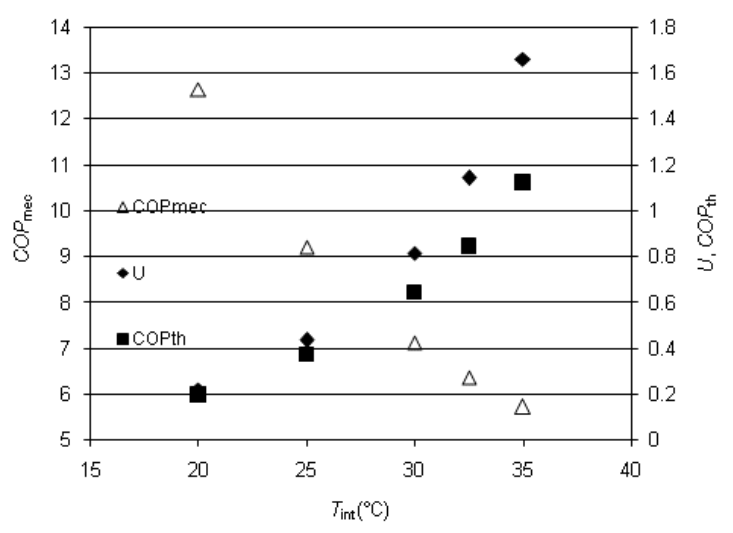

Figure 7. Variations of $U, C O P_{\text {th }}$ and $C O P_{\text {mec }}$ of the hybrid refrigeration system as a function of $T_{\text {int }}$ for $T_{\mathrm{B}}=80^{\circ} \mathrm{C}, T_{\mathrm{C}}=$ $40^{\circ} \mathrm{C}$ and $T_{\mathrm{E}}=5^{\circ} \mathrm{C}$

Furthermore, Figure 8 highlights the fact that when the temperature of the intercooler increases, the $C O P_{\text {mec }}$ of the hybrid system degrades while the surface of the solar collector decreases. This decrease can be explained by a lower contribution of the ejector subsystem in the production of the same cooling capacity.

Figure 9 shows that the variation of the temperature $T_{\mathrm{E}}$ affects not only the vapor compression sub-cycle but also the ejector sub-cycle. Indeed, it shows that when $T_{\mathrm{E}}$, increases, the $C O P_{\text {mec }}$ of the hybrid system increases while the surface area of the solar collector $A_{\mathrm{SC}}$ decreases. 


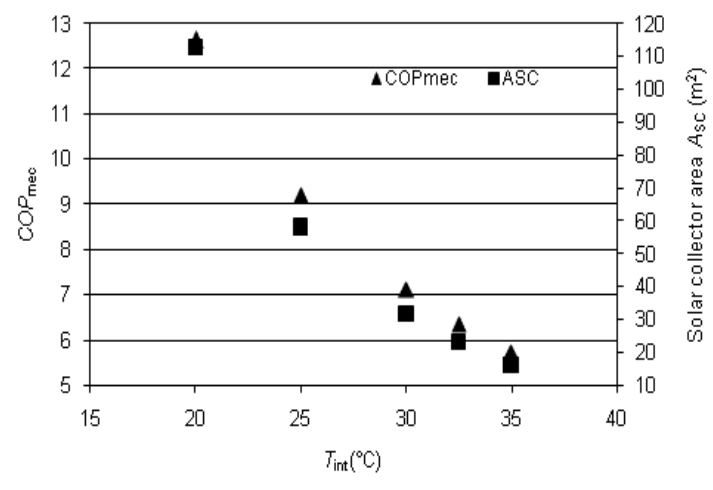

Figure 8. Variations of the $C O P_{\text {mec }}$ of the hybrid refrigeration system and the solar collector surface $A_{\mathrm{SC}}$ as a function of $T_{\text {int }}$ for $T_{\mathrm{B}}=80^{\circ} \mathrm{C}, T_{\mathrm{C}}=40^{\circ} \mathrm{C}$ and $T_{\mathrm{E}}=5^{\circ} \mathrm{C}$

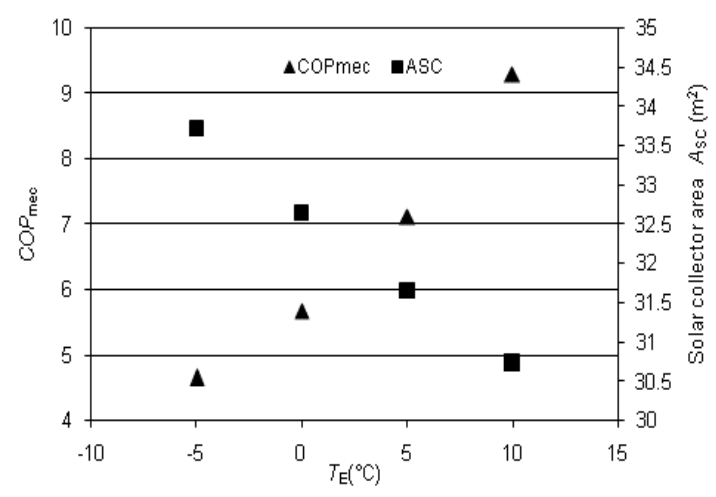

Figure 9. Variations of the $C O P_{\mathrm{mec}}$ of the hybrid refrigeration system and the solar collector surface $A_{\mathrm{SC}}$ as a function of $\mathrm{T}_{\mathrm{E}}$ for $T_{\mathrm{B}}=80^{\circ} \mathrm{C}, T_{\mathrm{C}}=40^{\circ} \mathrm{C}$ and $T_{\mathrm{int}}=30^{\circ} \mathrm{C}$

\section{CONCLUSIONS}

For a cooling capacity and temperatures of the phase change at the boiler, condenser, intercooler and evaporator fixed, the model presented in this work allows to determine the main geometrical parameters of the ejector and its entrainment ratio, the thermal and mechanical coefficient of performance as well as the surface of the solar collector of a hybrid compression / ejection refrigeration system.

In particular, for air conditioning operating conditions, the results obtained show that the hybrid refrigeration system allows to reach $C O P_{\text {mec }}$ values much better than those of the conventional vapor compression cycle. Indeed, an increase greater than $50 \%$ has been observed. This saving in electrical energy, in addition to the use of natural refrigerant $\left(\mathrm{H}_{2} \mathrm{O}\right)$ and low ecological impact fluid (R1234yf) make the hybrid refrigeration system using solar energy an environmentally acceptable system that can compete with the conventional vapor compression refrigeration system.

This work can be continued by testing other natural fluids such as propane R290 or isobutane R600a.

\section{REFERENCES}

[1] Eames, I.W., Aphornratana, S., Haider, H. (1995). A theoretical and experimental study of a small-scale steam jet refrigerator. International Journal of Refrigeration, 18(6): $\quad 378-386 . \quad$ http://doi.org/10.1016/01407007(95)98160-M

[2] Huang, B.J., Chang, J.M., Wang, C.P., Patrenko, V.A. (1999). A 1-D analysis of ejector performance. International Journal of Refrigeration, 22(5): 354-364. http://doi.org/10.1016/S0140-7007(99)00004-3

[3] Riffat, S.B., Omer, S.A. (2001). CFD modeling and experimental investigation of an ejector refrigeration system using methanol as the working fluid. International Journal of Energy Research, 25(2): 115-128. http://doi.org/10.1002/er.666

[4] Sriveerakul, T., Aphornratana, S., Chunnanond, K. (2007). Performance prediction of steam ejector using computational fluid dynamics: Part 1. Validation of the CFD results. International Journal of Thermal Sciences, 46(8): http://doi.org/10.1016/j.ijthermalsci.2006.10.014

[5] Sriveerakul, T., Aphornratana, S., Chunnanond, K. (2007). Performance prediction of steam ejector using computational fluid dynamics: Part 2. Flow structure of a steam ejector influenced by operating pressures and geometries. International Journal of Thermal Sciences, 46(8):

823-833. http://doi.org/10.1016/j.ijthermalsci.2006.10.012

[6] Chunnanond, K., Aphornratana, S. (2004). Ejectors: Applications in refrigeration technology. Renewable and Sustainable Energy Reviews, 8(2): 129-155. http://doi.org/10.1016/j.rser.2003.10.001

[7] Boumaraf, L., Lallemand, A. (1999). Performance analysis of a jet cooling system using refrigerant mixtures. International Journal of Refrigeration, 22(7): 580-589. http://doi.org/10.1016/S0140-07(99)00016-X

[8] Boumaraf, L., Haberschill, P. (2017). performance of a solar-driven ejector refrigerating system using fluids with low ecological impact. International Journal of Energy, Environment and Economics, 24(4): 393-401.

[9] Rusly, E., Aye, Lu, Charters, W.W.S., Ooi, A. (2005). CFD analysis of ejector in a combined ejector cooling system. International Journal of Refrigeration, 28(7): 1092-1101. http://doi.org/10.1016/j.ijrefrig.2005.02.005

[10] Boumaraf, L., Lallemand, A. (2009). Modeling of an ejector refrigerating system operating in dimensioning and off- dimensioning conditions with the working fluids R142b and R600a. Applied Thermal Engineering, 29(23): $265-274$ http://doi.org/10.1016/j.applthermaleng.2008.02.020

[11] Boumaraf, L., Lallemand, A. (2007). Comparaison des performances optimales d'un éjecteur dimensionné selon les modèles à pression constante et à section constante. In: Proceedings of the 13th International Thermal Meetings, Albi-France, 1: 371-375.

[12] Boumaraf, L., Haberschill, P., Lallemand, A. (2014). Investigation of a novel ejector expansion refrigeration system using the working fluid R134a and its potential substitute R1234yf. International Journal of Refrigeration, $\quad 45$ : 148-159. http://doi.org/10.1016/j.ijrefrig.2014.05.021

[13] NIST Standard Reference Database 23, Version 7.0

[14] Huang, B.J., Petrenko, V.A., Samofatov, I.Y., Shchetinina, N.A. (2001). Collector selection for solar ejector cooling system. Solar Energy, 71(4): 269-274. http://doi.org/10.1016/S0038-092X(01)00042-1 


\section{NOMENCLATURE}

A ejector section area, $\mathrm{m}^{2}$

$A_{\mathrm{SC}} \quad$ solar collector surface, $\mathrm{m}^{2}$

$\mathrm{COP} \quad$ coefficient of performance

$C_{\mathrm{P}} \quad$ constant pressure specific heat, $\mathrm{J} . \mathrm{kg}^{-1} \cdot \mathrm{K}^{-1}$

$d \quad$ diameter, $\mathrm{m}$

GWP Global Warming Potential

$h \quad$ specific enthalpy, $\mathrm{J} \mathrm{kg}^{-1}$

$I_{\mathrm{G}} \quad$ global incident solar radiation, $\mathrm{W} / \mathrm{m}^{2}$

$M \quad$ Mach number

$\dot{m} \quad$ mass flow rate, $\mathrm{kg} . \mathrm{s}^{-1}$

ODP Ozone Depletion Potential

$P \quad$ pressure, $\mathrm{Pa}$

NSW Normal Shock Wave (Fig.3)

$Q$

$\dot{Q}$

$R$

$T$

$U$

V

$\dot{W}$

w

specific entropy, $\mathrm{J}_{\mathrm{kg}}{ }^{-1} \cdot \mathrm{K}^{-1}$

heat amount, $\mathbf{J}$

thermal power, $\mathrm{W}$

specific gas constant, $\mathrm{J}_{\mathrm{kg}} \mathrm{kg}^{-1} \mathrm{~K}^{-1}$

temperature, $\mathrm{K}$ or ${ }^{\circ} \mathrm{C}$

ejector entrainment ratio, $\left(=\dot{m}_{\mathrm{S}} / \dot{m}_{\mathrm{p}}\right)$

fluid speed, $\mathrm{m} . \mathrm{s}^{-1}$

mechanical power, $\mathrm{W}$

Specific work, J. $\mathrm{kg}^{-1}$

\section{Greek symbols}

$\varepsilon \quad$ heat exchanger efficiency

$\eta \quad$ isentropic efficiency

$\eta_{\mathrm{SC}} \quad$ thermal efficiency of the solar collector

$\eta_{\mathrm{P}} \quad$ pump efficiency

$\rho \quad$ density, $\mathrm{kg} \cdot \mathrm{m}^{-3}$

\section{Subscripts, Superscripts}

B

boiler

C condenser

comp compressor

D diffuser

E evaporator

G global

int intercooler

is isentropic process

m mixing

mec mechanical

$\mathrm{P} \quad$ primary fluid (or nozzle)

S secondary fluid (or nozzle)

th thermal

throat section of the primary nozzle

$\mathrm{i}, \mathrm{j}, \mathrm{k} \quad$ locations in the ejector

$1,2, . ., 13 \quad$ locations in the hybrid cycle 